\title{
Discrimination against Women in Accessing Higher Education in Cambodia
}

\author{
Sophorn Tuy \\ Center for the Study of Humanitarian Law (CSHL), Royal University of Law and \\ Economics (RULE) \\ Email: sophorn@elbbl-cshl.org
}

\begin{abstract}
Young women in Cambodia face challenges in accessing higher education. Social norms, financial constraints and other problems are the main root causes in the limitation of opportunities for women to pursue higher education. Social norms of the older generation in Cambodia remain from the past and they often think that it is not necessary for women to study in higher education institutions since a women's role is to just be a housewife after marriage. Another restriction on women's access to higher education is that they often have financial problems in supporting their education. Some women have to work in order to support their families, so they have no chance to pursue higher education. Additionally, since most universities are located in cities, parents often feel insecure about their daughters studying far away from home. Currently there is the increased enrollment of young women in higher education due to government action, as it has ratified international conventions and enacted domestic laws. As well, there is government cooperation with NGOs to establish some strategies and action plans to promote and protect gender equality in all sectors, including the education sector, by improving scholarship opportunities or building dormitories for female students to live in while studying at university. However, these supports cannot provide access to higher education for young women in all areas in the Kingdom of Cambodia, and Cambodia has not yet enacted specific laws to promote the participation of women in higher education. This research aims to explore the opportunities that have been provided to young women to pursue higher education, particularly at the university level. After exploring the opportunities, the researcher will analyze data regarding the challenges for women in accessing higher education. Finally, the researcher will provide some possible recommendations to address these challenges. This research utilized multiple methods, including desk review and structured interviews. Interviews were conducted face-to-face and in focus group discussions (FGD). Desk review focuses on all relevant international and national laws, strategic and action plans related to the promotion of women studying at university and the de facto equality of that issue.
\end{abstract}

Keywords: Gender Equality, Gender Equity, Higher Education, Gender Discrimination 


\section{INTRODUCTION}

Higher education is a crucial element of development and works to improve the quality of life and wellbeing of people around the world. ${ }^{1}$ While higher education is valuable, not everyone can complete a university degree. ${ }^{2}$ There are two major factors which impact access to higher education: financial problems and discrimination. ${ }^{3}$ Southeast Asia is still facing challenges in the higher education sector. ${ }^{4}$ At present, all countries in the Southeast Asia region are promoting and reforming their higher education systems, and they cooperate well with each other. $^{5}$

Improving women's capacity to access education, develop skills, and find employment can reduce the rates of poverty, illiteracy, and improve the health of women. ${ }^{6}$ When women lack the capacity to access and complete higher education it causes a lack of developed human resources throughout the whole country. ${ }^{7}$ Based on the 2016 Human Development Report, more than one hundred and fifty countries have legally discriminated against women. One hundred countries discriminate against women in the work force simply because they are women. ${ }^{8}$ Gender inequality is not an isolated or new issue; it exists worldwide. ${ }^{9}$ Gender inequality has been an issue for long time. Almost all countries in the world have a gender gap. Inequality in society is a consequence of inequality in education. ${ }^{10}$ Therefore, education, gender equality, and women's empowerment are important factors for reducing poverty and improving economic growth in developing countries. ${ }^{11}$ If women can have the opportunity to complete higher education they can improve their future careers prospects and earn a higher income. Education is a human right and an important tool to promote equality, development, and peace. Investing in education for women and girls can improve

1 The Role of Higher Education in Society: Quality and Pertinence (Paris, 1991).

2 Patrick Kyllonen, La importancia de la educación superior y el rol de los atributos no cognitivos en el éxito en dichas instituciones (2012).

3 Rhona K M Smith, International human rights law, eighth edition ed (New York, NY: Oxford University Press, 2018).

4 Thammika Songkaeo \& Loke Hoe Yeong, 'Defining Higher Education Issues and Challenges in Southeast Asia/ASEAN within the International Context' (2016) Head Found.

5 Ibid.

6 'Program of Action of the 1994 International Conference on Population and Development (Chapters I-VIII)' (1995) 21:1 Popul Dev Rev 187, online: https://www.jstor.org/stable/2137429.

7 USAID, Gender and Extreme Poverty (2015).

8 UNDP, Human Development Report 2016 (New York, 2016).

9 Progress towards the Sustainable Development Goals: Report of the Secretary-General (2017).

10 Ibid.

11 UNESCO Institute for Statistics, Global education digest 2010: comparing education statistics across the world. (Montreal: UNESCO Institute of Statistics, 2010). 
sustainable, economic development. ${ }^{12}$ Gender disparity in tertiary education mostly exists in developing countries, including the Arab States, Sub-Saharan Africa, and South Asia. ${ }^{13}$ Gender parity of education has proven to be a main factor in developing a country's economy because there is a higher skilled workforce. $^{14}$

Due to the improvement of higher education globally and regionally, the Royal Government of Cambodia (RGC) has strived to enhance the higher education system with equitable quality through the strengthening of national policies, legal framework, and institutions for enhancing education quality. ${ }^{15}$ Currently, Cambodia is considered a developing country and was ranked 109 out of 145 countries on the Gender Inequality Index in 2015. In terms of gender inequality in enrollment in tertiary education, Cambodia was ranked 127 out of 145 countries. ${ }^{16}$ As Cambodia moves towards middle-income status and regional integration, there is a need to promote equitable access to high quality education at all levels of society in order to compete in the free labor market. ${ }^{17}$ In Cambodia the poorest people hardly have post-secondary education opportunities. ${ }^{18}$ This is evident by examining the gender make-up of positions which require postsecondary education, such as the proportion of female lawmakers in the legislative body, which decreased from $21 \%$ in 2008 to $20 \%$ in $2013 .{ }^{19}$ RGC needs to address these issues in order to fix the gender gap, particularly in secondary and higher education due to the lack of locally available education facilities and traditional values that place lower primacy on girls and women. ${ }^{20}$ Cambodian women need greater opportunities for higher education so that they can compete for jobs in competitive markets. ${ }^{21}$ Gender inequality in higher education can provide women the right to work and economic. ${ }^{22}$

12 Ministry of Women Affairs, The Implementation of the Beijing Declaration and Platform for Action (1995) and the outcomes of the Twenty-third Special Session of the General Assembly (Pnom Penh, 2000).

13 Nich Chea, 'Higher Education in Cambodia Poor Rural Female Students' challenges, motivations, and coping strategies' (2015), online: https://gupea.ub.gu.se/handle/2077/39995.

14 Peter Fry and Rogéro Utui, Literature Review on Equity and Access to Tertiary Education in the Africa Region, ed (Africa, 2009).

15 Ibid.

16 UNDP, Human Development Report 2015 (New York, 2015).

17 Ministry of Women Affairs, Five Years Strategic Plan for Gender Equality and Empowerment of Women 2014-2018 (Ministry of Women Affairs, 2014).

18 Unesco, Global education monitoring report 2017/18: accountability in education : meeting our commitments (2017).

19 Ministry of Education Youth \& Sport, National Strategic Development Plan 2014-2018 (Pnom Penh, 2014).

20 Ibid.

21 UNESCO, UNESCO National Education Support Strategy (Pnom Penh, 2010).

22 Rany Rany, Ahmad Nurulazam Md Zain \& Hazri Jamil, 'Establishment of Institutional Policies for Enhancing Education Quality in Cambodian Universities' (2012) 1:1 Int J High Educ 112, online: http://www.sciedu.ca/journal/index.php/ijhe/article/view/1024. 
The enrollment rates of female students in Cambodian universities still show a gap because of these outlined obstacles. In response to these problems, international agencies co-operated with representatives from the Ministry of Education, Youth and Sports (MoEYS) in 2009 to address concerns in quality, capacity building, teacher training, and lack of gender equity and equality under the financial support of the Asian Development Bank. ${ }^{23}$

Since gender equality in access to higher education is a crucial factor for developing the human resources of a developing countries economy, this research will explore and analyze the opportunities and the challenges for Cambodian women to access universities based upon both de facto and de jure practices. This paper will examine, in depth, the current opportunities and issues of women's access to university and how the implementation of national laws and policies developed by state and non-state actors can protect and promote women to improve their access to universities in the future.

The main objectives of this research are to explore the opportunities that female students receive from relevant stakeholders for improving their access to university; analyze the main challenges for women to Access University; and recommend possible solutions to address the challenges for female students in accessing university. The researcher interviewed duty-bearers, including government officials from MoEYS and Ministry of Woman Affairs (MoWA), NGO staff, university lecturers and enrollment staff of each university, parents, university students, and a group of women who lost their chance to attend university.

The significance of this research will go beyond simply identifying the barriers; it will analyze the challenges of girls' access to university and assess the RGC's implementation of the Beijing Platform for Action (BPFA), the Convention on the Elimination of All Forms of Discrimination against Women (CEDAW), Sustainable Development Goals (SDG), and the Cambodia Constitution. This study's results will contribute to Cambodian society by promoting the reduction of the gender gap in access to higher education. This research will be useful in the protection and improvement of human rights and peace in ASEAN countries, specifically in Cambodia.

\section{PROTECTION AND PROMOTION OF WOMEN IN HIGHER EDUCATION UNDER THE CURRENT LEGAL FRAMEWORK}

For centuries, women all over the world have been discriminated against. This continues to be true, despite the historical advances in Europe towards individual freedoms and liberty, starting with the French and American Revolutions. ${ }^{24}$ For

23 Mary N Booth, 'Education and Gender in Contemporary Cambodia' (2014) 4:10 Int J Humanit Soc Sci 9.

24 Azizur Rahman Chowdhury \& Jahid Hossain Bhuiyan, eds, An introduction to international human rights law (Leiden; Boston: Brill, 2010). 
the purpose of establishing security and peace in the world after World War II (WWII), the United Nations (UN) adopted the UN Charter in 1945, and immediately thereafter adopted the Universal Declaration of Human Rights (UDHR) in December 1948. ${ }^{25}$ The rights of women to access higher education are protected under Article 26 of the UDHR. ${ }^{26}$ Another relevant universal instrument is the UN Educational, Scientific and Cultural Organization (UNESCO) Convention against Discrimination in Education adopted in 1960. The purpose of which is the elimination of discrimination in states' education systems and the promotion of equality of opportunity and treatment. ${ }^{27}$ The International Covenant on Civil and Political Rights (ICCPR) and The International Covenant on Economic, Social and Cultural Rights (ICESCR) were adopted in 1966 and came into force in 1976 in accordance with the provision of Article 49 of ICCPR and Article 27 of the ICESCR. ${ }^{28}$ The ICCPR does not have a specific article for the protection of women's access to higher education. However, a women's right to access higher education is explicitly protected under Article $13(2$, c) of ICESCR. ${ }^{29}$ However, even though this act incorporates equality, it does not specifically reference women. ${ }^{30}$ The specific elimination of discrimination against women was adopted by the General Assembly in CEDAW in 1979. Article 10 of CEDAW states that "State Parties shall take all appropriate measures to eliminate discrimination against women in order to ensure to them equal rights with men in the field of education and in particular to ensure on a basis of equality of men and women..." 31 This article also includes vocational training and continued education, the removal of stereotypes from the education system, equal access to finding education and reducing female drop-out rates at all levels. ${ }^{32}$ The Vienna Declaration of the World Conference on Human Rights 1993, Paragraph 33 states that all states that have ratified CEDAW have made a legally binding commitment to protect, respect, and promote women in order to end all forms of discrimination against them. ${ }^{33}$ The CEDAW Committee was created to monitor state parties. Each state must submit a report periodically to the Committee and then the Committee is tasked with providing recommendations for future actions for the government. ${ }^{34}$ Other aspects of the universality of a human's right to

25 Ibid.

26 'Universal Declaration of Human Rights', (1945), online: http://www.un.org/en/universaldeclaration-human-rights/index.html.

27 Daniel Moeckli et al, eds, International Human Rights Law, third edition ed (Oxford, New York: Oxford University Press, 2017).

28 Chowdhury \& Bhuiyan, supra note 24.

29 OHCHR, International Covenant on Economic, Social and Cultural Rights (1966).

30 Chowdhury \& Bhuiyan, supra note 24.

31 CEDAW, (entered into forced 3 September 1981), art. 10.

32 Ibid, art. 10.

33 Smith, supra note 3.

34 Optional Protocol of Convention on Elimination of all forms of Discrimination against women (2000). 
education were considered during the United Nations endorsement of the BPFA which was adopted by the Forth Conference on Women in 1995. The purpose of this is to advance the ability of women to receive equal rights, responsibilities, and opportunities to be involved in national and international organizations, government decisions, and policy making processes. ${ }^{35}$ The action plan of the declaration was to improve the quality of education and provide equal opportunities for women and men in terms of accessing education at all levels. ${ }^{36}$

Education rights are also guaranteed by regional human rights instruments in Southeast Asia. ${ }^{37}$ Article 2 of the Protocol of European Convention of Human Rights (ECHR) provides that "no person shall be denied the right to education"; 38 Article 10 of the European Social Charter (ESC) sets out that States must "provide or promote... for access to higher technical and university education..."; 39 Article 17 (1) of African Charter of Human Rights and People's Rights (ACHPR) specifies that "every individual shall have the rights to education"; ${ }^{40}$ Article 13 of the Additional Protocol to the American Convention on Human Rights in the Area of Economic, Social and Cultural Rights (Protocol of San Salvador) states that "everyone has right to education"; ${ }^{41}$ Article 34 of Arab Charter on Human rights (ACHR) provides that " $[\mathrm{t}]$ he eradication of illiteracy is a binding obligation and every citizen has a right to education... free and both secondary and university education shall be made easily accessible to all"; ${ }^{42}$ and finally, Principle 31 of the non-binding ASEAN Human Rights Declaration has a similar statement to other international and regional conventions: ${ }^{43}$ "(1) [e]veryone has the rights to education, (2)...higher education shall be equal accessible to all on the basis of merit." 44

In Cambodia the progress of implementing CEDAW is continuously improving. Based on the final Fourth and Fifth National Report of the Kingdom of Cambodia, the state provides equal rights for men and women to access

35 UN Women, Beijing Declaration and Platform for Action: The Fourth World Conference (Beijing, 1995).

36 Ibid, para. 80.

37 Moeckli et al, supra note 27.

38 Protocol of ECHR, (entered into forced 1 June 2010).

39 Council of Europe, European Social Charter (Revised) (1996).

40 African Charter on Human Rights and People's Rights, OAU Doc. CAB/LEG/67/3 rev. 5, 21 I.L.M. 58 (1982), (entered into force 21 October 1986).

41 Organization of American States OAS, 'Additional Protocol to the American Convention on Human Rights in the Area of Economic, Social and Cultural Rights (Protocol of San Salvador), 14 November 1988' (1989) 16 Annu Rev Popul Law 1,234.

42 Arab Charter on Charter on Human Rights (entered into forced 16 March 2008).

43 Moeckli et al, supra note 27.

44 ASEAN Human Rights Declaration and Phnom Penh Statement on the Adoption of the ASEAN Human Rights Declaration (AHRD) (entered into forced February 2013). 
education at all levels. ${ }^{45}$ The following are achievements that the RGC has made over the years:

- The RGC became a party of CEDAW on 14 November 1992 and signed on the BPFA for the promotion of the status of women has submitted reports since $1995 .{ }^{46}$

- Article 31 of the Constitutional of Kingdom of Cambodia states that, "The Kingdom of Cambodia recognizes and respects human rights as determined in the Universal Declaration on Human Rights..." ${ }^{47}$

- Another aspect of the Constitution states that "Khmer citizens of both sexes have the right to participate actively in the political, economic, social and cultural life of the nation." 48

- The specific article of the Constitution of the Kingdom of Cambodia that relates to education states, "[t]he State shall protect and promote the right of the citizen to quality education at all..."49

- Finally, the Law on Education was adopted in 2004 in compliance with the Constitution of the Kingdom of Cambodia, which required the State to uniform the education system to adhere with the principle of free access to education to all..$^{50}$

The RGC has some related laws on gender equality in education. However, there is no specific article promoting and protecting girls and women in accessing higher education, and certain relevant law enforcement has not been so strong. Cambodian lawmakers are men; thus, it is hard to enforce these specific laws. There is a history of making laws relative to cultural norms. ${ }^{51}$ Thus, some relevant laws were passed but lack enforcement.

\section{PROTECTION AND PROMOTION OF WOMEN'S RIGHT TO HIGHER EDUCATION UNDER CAMBODIA'S INSTITUTIONAL MECHANISMS}

The Department of Higher Education (DHE) is under MoEYS. The DHE has assured the provision of full staff training and the enhancement of research in science, technology, culture, and society. Additionally, the DHE has built up the policy and planned for developing the academic education system; managed and coordinated public education academic institutions and private institutions; recruited students to study a basic, foundation academic year; selected and

45 Ibid.

46 Ministry of Women Affairs, Gender: Gender Mainstreaming Institutional, Partnership and Policy Context Cambodia Gender Assessment (Pnom Penh, 2014).

47 Constitution of the Kingdom of Cambodia, 1993, article 31.

48 Ibid, article 35.

49 Ibid, art. 65.

50 Education Law. art. 1.

51 Ibid. 
managed students in the country; and submitted activity reports to the Minister in charge according to the deadline. ${ }^{52}$ The DHE created the Gender Mainstream Action Group (GMAG) as per Article 18, 12 of Enhancing Education Quality Project (EEQP) and Sub-Decree 84 on Organization and Conducts of MoEYS. ${ }^{53}$ Thus, the DHE is the main department for promoting greater access of female students to higher education. Response to Equal Access (EA) has included gender equality policies in the education sector. Since 2008, MoEYS has cooperated with relevant ministries and other stakeholders and has had remarkable results in policies and plans of gender mainstreaming. ${ }^{54}$ The GMAG of DHE has also cooperated well with MoWA and other relevant stakeholders in striving to mainstream gender equality to all areas in Cambodia to increase the enrollment in university. The RGC also provides scholarships to female students to study abroad. Since 1990, the Recruitment Commission's rules have been such that if the same score is achieved by a man and a woman, the Commission will recruit the woman. ${ }^{55}$ For ensuring gender equality, the RGC has provided many measures with the purpose of enabling young women to obtain an education at all levels by providing scholarships, health services, and preventing drop-outs by building dormitories for female students. ${ }^{56}$ MoEYS provides scholarships for outstanding students, poor students, female students, and students from remote areas. The Ministry also provides dormitories to poor female students from provinces to help them pursue their studies. MoEYS provided $10 \%$ of all scholarships to female students from 2002 to 2006. After 2006, MoEYS changed its policy so that it provides $15 \%$ of scholarships to female students. In the academic year 2008-2009, the number of female students in tertiary education increased to $38.47 \%$ from only $32.06 \%$ in the academic year of $2004-2005 .{ }^{57}$ Cambodia hosted $826 \mathrm{Khmer}$ and foreign scholarship students in dormitories, $72.40 \%$ of which were female. ${ }^{58}$ The gender disparity in education has been reduced at all levels due to more scholarships for female students; the amount of financial support is USD 1,200,000 from the government budget and development partners (DPs) including Action Aid, UNICEF, UNESCO, Plan International, and The United Nations

52 Organization and Functioning of Ministry of Education Youth and Sport Royal Government of Cambodia, Sub-decree No. 84 ANKr. BK (9 June 2009), article 23.

53 Ministry of Education Youth \& Sports, Annual Report 2009 and Annual Plan 2010: Enhancing Education Quality Project”, ADB Grant No. 0090 - CAM (SF) (Pnom Penh, 2010).

54 Ministry of Women \& Affairs, Education: Gender in Education and Vocational Training Cambodia Gender Assessment (Pnom Penh, 2014).

55 Committee on the Elimination of Discrimination against Women, Consideration of reports submitted by States parties under article 18 of the Convention on Convention on the Elimination of All Forms of Discrimination against Women (Cambodia, 2006).

56 Ministry of Education Youth \& Sports, The Education, Youth and Sport Performance in the Academic Year 2015-2016 and Goals for the Academic Year 2016-2017, 21-22-23 March 2017 (Pnom Penh, 2017).

57 Ministry of Women Affairs, supra note 12.

58 Ministry of Education Youth \& Sports, supra note 56. 
Development Programme (UNDP). ${ }^{59}$ The scholarship increase for female students pursuing a Bachelor Degree was 30.93\% comparing the year 2015-2016 to the previous year. ${ }^{60}$ In 2015-2016, Cambodia sent 527 students (28.60\% female) to study in Thailand, the People's Republic of China, Vietnam, Japan, Laos, Russia, Singapore, Cuba and the Philippines. ${ }^{61}$ There has been progress in improving scholarships and dormitories for female students pursuing higher education which have been provided by the RGC and other development partners and NGO projects. New visions of education beyond 2015 by the National Education for All Committees has included encouraging female students to participate in education equally with men, reducing gender disparity between female and male students through supporting gender programs and inspiring female students to make their own decisions. ${ }^{62}$ In general, the improvement in the enrollment in higher education between 2009 and 2013 increased by 57\% from 137,253 to 216,053 students, and the number of scholarship students increased by $2.35 \% .{ }^{63}$ The number of higher education institutions increased from 10 in $1990^{64}$ to 121 in $2016^{65}$ which then met the minimum standards of Higher Education Institution (HEI) Accreditation System. MoEYS ran a campaign for education and disseminated information about human rights by providing education to communities and students' parents, increasing awareness of human rights and education across the country. ${ }^{66}$ The program budget for the gender program for education was allocated by sub-sector. The budget has been allocated by MoEYS since 2007. MoEYS is the main actor in enhancing education quality at all levels and MoWA works with MoEYS and other relevant stakeholders to eliminate gender stereotypes and incorporate human rights courses into school textbooks and teaching methodologies.

MoWA has a duty to protect and promote women's rights in education, health, economic empowerment, and legal protection. ${ }^{67}$ This Ministry aims to promote the status of women in Cambodia. MoWA was created to lead, facilitate, and coordinate the effort for gender equality and women's empowerment in the country. ${ }^{68}$

59 Ministry of Women Affairs, supra note 17.

60 Ministry of Education Youth \& Sports, supra note 56.

61 Ibid.

62 Education for All 2015 National Review Report (Pnom Penh, 2015).

63 Education Strategic Plan 2014-2018(Pnom Penh, 2014).

64 Vicheth Sen, 'Cambodia's Higher Education Structure and the Implications of the 2015 ASEAN Economic Community' (2013) CDRI Annu Dev Rev 24.

65 Ministy of Education, Youth \& Sport. Achievement in School Year 2014-2015 \& 2015-2016 (Pnom Penh, 2017).

66 Committee on the Elimination of Discrimination against Women, supra note 55.

67 The Organization and Functioning of the Ministry of Women's Veteran's Affairs, Sub-Decree No. 88 ANKr. BK (7 October 1999), article 3.

68 History of MoWA (2017). 
MoWA's mission is to reduce gender gaps and promote access to productive resources for all women. Thus, the Ministry's achievements can be seen through the mainstreaming of gender in law, government reforms, and in national and sectorial policies. This has included: coordinating and monitoring implementation of specific programs and policies for gender equality; implementing measures to remove barriers, discrimination and gender stereotypes that impede full participation of women in public life; undertaking initiatives to encourage men and boys to support gender equality and be involved in housework and the care of children and dependents; and targeting the needs of the most vulnerable women and girls. MoWA has achieved those goals by collaborating with line ministries and civil society organizations, including women's organizations, the private sector, universities, research centers, development partners and individuals themselves. ${ }^{69}$ After Cambodia's endorsement of BPFA and in collaboration with line ministries and Civil Society Organizations (CSO), MoWA has increased the enrollment rate of female students in school. ${ }^{70}$ The achievement of narrowing the gender gap in literacy within 15 to 25 years old has been improving since 2004 and the proportion of female to male literacy rate was more than $99 \%$ in 2011 compared to 91.3 in $2004 .^{71}$

MoWA has had a role both directly and indirectly increasing female enrolment in university. Based on the achievements of national five years of strategic plan (Neary Rattanak III), MoWA, in collaboration with other relevant ministries and stakeholders, has had remarkable results in promoting legal policies and programs. These have been in response to the program of Equitable Access to Higher Education (EAHE) which has successfully seen economic improvements of women, elimination of all forms of discrimination against women in all sectors, improvements of women's health and increased scholarships to female students, as well as promoting social morality, the value of women in Cambodia families, and the promotion of women in all sectors. ${ }^{72}$

The Cambodian National Council for Women (CNCW) is the mechanism for supporting the RGC to promote the status and roles of women and to eliminate all forms of discrimination against women. ${ }^{73}$ It also follows up with the implementation of the international conventions relevant to women's rights by giving recommendations to the RGC and compiling periodic reports on the implementation of CEDAW provisions. ${ }^{74}$ The Permanent Secretariat General (PSG) is tasked with assisting with the progress of the national report on CEDAW for the $\mathrm{CNCW}$ and assisting with approving the submission of the state report

69 Vision and Mission of MoWA (2017).

70 Ibid.

71 Annual Progress Report 2013: Achieving Cambodia's Millennium Development Goals (Pnom Penh, 2014).

72 Ministry of Women Affairs, supra note 17.

73 Cambodian National Council for Women, Cambodian National Council for Women (2001).

74 Ibid. 
before it is sent to the UN. The PSG observes the status of women, gives recommendations to the RGC and the World Conference for Women, and promotes CEDAW to commune levels. The PSG also checks national and international laws relating to women in order to follow up, evaluate and give recommendations. The PSG cooperates with ministries, institutions, national and international organizations, and civil societies in order to provide recommendations to $\mathrm{CNCW}$ and make decisions before they are sent to the RGC. Additionally, there is the Cambodian NGO Committee on CEDAW (NGO-CEDAW) which was officially registered in 2009. NGO-CEDAW's duty is to monitor and promote the implementation of CEDAW in Cambodia, as well as advocating for women's rights by submitting an NGO Shadow Report. This is in coalition with more than thirty other NGOs. ${ }^{75}$

\section{PROTECTION AND PROMOTION OF WOMEN IN HIGHER EDUCATION UNDER CAMBODIA'S NATIONAL POLICIES AND ACTION PLANS}

Cambodia's economy has been affected by international and regional integration, so the development of higher education needs to follow international and regional trends. In response to this situation, MoEYS has strived to formulate the Cambodia Higher Education Vision 2030 (CHEV 2030). The CHEV 2030 advocates for comprehensive equity and access for all qualified students to have the opportunity to study at Higher Education Institutes and complete a quality program. ${ }^{76}$ Goal Number Four of the SDGs outlines the need for inclusive and equitable quality education and the promotion of lifelong learning opportunities for all. ${ }^{77}$ RGC established the National Strategic Development Plan NSDP (20142018) which aims to increase scholarships for girls in upper secondary and higher education, raise awareness of parents in order to increase girls' access to education, increase the participation of women in all areas of education service delivery and management and promote gender responsive social behavior. ${ }^{78}$

The NSDP aims at promoting women in higher education. Under Paragraph (4.192), the RGC, during the Fifth Legislature, will continue to implement CEDAW and other relevant international treaties that pertain to gender equality and women's rights, as well as its policy in order to increase educational opportunities for female students by increasing scholarships, access to accommodation and safe transportation and increasing the number of female

75 The Cambodian NGO Committee on CEDAW (2017).

76 Ministry of Education Youth \& Sports, Policy on Higher Education Vision 2030 (Pnom Penh, 2014).

77 Ministry of Education Youth \& Sports, Rapid Integrated Assessment - Cambodia \{SDG\} Profile Card (Pnom Penh, 2016).

78 Ministry of Education Youth \& Sport, supra note 19. 
teachers. ${ }^{79}$ Additionally, under Paragraph (4.193) the RGC plans to continue to implement gender equality policies through mainstreaming gender in all programs in order to improve education for women and girls. ${ }^{80}$ Furthermore, under Paragraph (4.196) the RGC aims to increase the number of scholarships for girls in upper secondary and higher educations and to increase the participation of women in all areas of education delivery and management. ${ }^{81}$

The Education Strategic Plan (ESP), 2014-2018 was officially launched in 2014. This plan was developed by MoEYS and is relevant to national and subnational level stakeholders and partners for enhancing capacity in educational planning. ${ }^{82}$ The ESP aims to produce lifelong learning with high quality education at all levels and plans to create opportunities for accessing technical and specialized skills for all. In response to its goals, the ESP created a clear relationship between national and educational strategies. MoEYS plans to provide high quality education with equitable access to for all. ${ }^{83}$

The Millennium Development Goals (MDGs) were adopted in September 2000 by all 189 member-states of the UN General Assembly. The RGC committed to achieving the MDGs and they are fundamental to Cambodia's development strategy. ${ }^{84}$ The RGC adopted the eight universally agreed upon MDGs in 2003 for improving the country's development. ${ }^{85}$ There were nine goals included in the MDGs. The United Nations Country Team (UNCT) committed to work together in support of nations to achieve those nine goals in 2011 until 2015. Goal number three requires governments to promote gender equality and empower women by reducing gender gaps in education. ${ }^{86}$ Based on the Achieving Cambodia's Millennium Development Goals: Gap Analysis, there has been much progress as seen by the improved ratio of female to male in tertiary education. However, the ratio remains far below the target. ${ }^{87}$

Beyond 2015, new visions of education by the National Education for All Committees includes: the encouragement of female students to participate in education equally with men; reducing the gender disparity between female and male students through supporting gender programs; and inspiring female students to make their own decision. ${ }^{88} \mathrm{MoWA}$ and $\mathrm{CNCW}$ are responsible for monitoring

79 Ibid.

80 Ibid.

81 Ibid.

82 Anne Lemaistre, Remarked by Mrs. Anne Lemaistre, Chair of Education Sector Working Group (ESWG) UNESCO Representative in Cambodia (2015).

83 Ministry of Education Youth \& Sport, supra note 19.

84 United Nations, United Nations Millennium Declaration (2000).

85 Our Work-Cambodia MDG', (2017), online:

<http://www.kh.undp.org/content/cambodia/en/home/library/mdg.html>.

86 Ministry of Planning, Achieving Cambodia's Millennium Development Goals (Pnom Penh, 2010).

87 Sherif Rushdy, Achieving Cambodia's Millennium Development: goal-gap analysis (2009).

88 Supra note 62. 
and evaluating policies and programs to implement the RGC's goals for promoting gender equality and empowerment of women. ${ }^{89}$ In collaboration with MoWA, and in line with national and sub-national level analysis, the effectiveness in implementation of five years strategic plans "Neary Rattanak I-III" and "Neary Rattanak IV" was considered an important part of the RGC's NSDP 2014-2018. ${ }^{90}$ These plans increase women's access to education and create behavioral change regarding gender equality by gender mainstreaming and women's empowerment in the framework of economic growth and social protection and services. ${ }^{91}$ Promotion of gender equality in education is an objective part of Neary Rattanak IV. The Neary Rattanak IV aims to provide education services by raising awareness, having social accountability measures, and providing scholarships and other financial assistance. It is happening is in order to increase the participation of women in all areas of education delivery and management as well as to promote a gender responsive attitude. ${ }^{92}$

\section{OPPORTUNITIES OFFERED TO FEMALE CAMBODIAN STUDENTS TO PURSUE UNIVERSITY}

MoEYS initated the project "Ensure Inclusive and Equitable Quality Education and Promote Lifelong Learning Opportunities for All." According to the report from the Education Congress Year 2015-2016 ${ }^{93}$,

it was successfully implemented; the amount of higher education institutions increased to 121 by 2016. In addition, the total number of female students to pursue higher education was 219,069 (43.69\%). The number of females who studied associate degree was $47.94 \%$. Compared to the previous year, number of associate degree students decreased by 1,224 students (70.50\%). Out of the total, $37.71 \%$ of female students had a chance to receive a scholarship to pursue an associate degree. There were $47.42 \%$ of female students who graduated with an associate degree in 2016. This number increased $51.88 \%$ compared to the previous year. The total percentage of female students pursuing a bachelor's degree was $46.05 \%$; this decreased by $44.79 \%$ compared to the previous year. The number of female students who received scholarships to pursue bachelor's degrees in 20152016 was $45.94 \%$; this was an increase by $30.93 \%$ compared to the previous year. There were 20,918 (46.90\%) female bachelor's graduate students compared to the previous year it decreased by 1,569 (33.71\%). Scholarships for female graduate students accounted to $3,187(43.04 \%)$. Compared to the previous year, this number increased by 371 (70.80\%). There were $21.78 \%$ of female students pursuing a

Ministry of Women Affairs, supra note 17.

90 Ibid.

91 Ibid.

92 Ibid.

93 Ministry of Education Youth \& Sports, supra note 56. 
master's degree and 5.13\% pursuing a doctoral degree in 2015-2016. ${ }^{94}$ Since 2015, the policy of providing scholarships to students has been divided into four categories: merit based (60\%), female student based (15\%), poor family based (20\%), and students from rural or disadvantaged areas based (5\%). ${ }^{95}$ In 2015-2016, the government organized examinations and selected $59.61 \%$ of whom were female to enroll in their bachelor degree, including 54.43\% female students among all merit based, 577 female students based, 57.80\% female students among all poor family based, and 37.62\% female among all from disadvantaged areas based. The scholarship students included 97 Vietnamese students (28.86\% female), 49 Laotian students (32.65\% female), and 15 students from the People's Republic of China (93.34\% female). ${ }^{96}$ Female students are a priority if their score or other conditions are equal to men. MoEYS has collaborated with Smart Company since 2015 to support 10 scholarships for merit students every year and give them a stipend of 200 US dollars per month. All scholarships are prioritized to female students. ${ }^{97}$

According to the reports from 105 students, $46.67 \%$ of those students have chances to get scholarships to pursue university degrees. Most of those students are female. There are $14.29 \%$ scholarships offered by government, $53.06 \%$ offered by NGOs, and $32.65 \%$ offered by universities. Among all of the scholarship students, $65.30 \%$ of the students might not have had a chance to pursue university if they were not offered scholarships. ${ }^{98}$ Based on the results, there are noticeable scholarships offered to female students in each university, but the research shows that the scholarships offered by the universities are the highest rank, then NGOs ranked number two, and the last ranked is the government. Most of those students might have not been able to pursue university degrees if they lost their chance to get scholarships. Thus, scholarships are important for them to pursue higher education.

\section{CHALLENGES FOR GIRLS/WOMEN IN ACCESSING UNIVERSITY}

One thesis entitled, "Higher Education in Cambodia: Poor rural female students' challenges, motivations, and coping strategies" details that the challenges of female students in participating in university are due to gender values, lack of financial resources, social problems, and safety concerns. ${ }^{99}$ A MoWA report also mentions that a barrier in accessing university for women includes social norms and

$\begin{array}{ll}94 & \text { Ibid. } \\ 95 & \text { Ibid, page 53-54. } \\ 96 & \text { Ibid } \\ 97 & \text { Ibid. } \\ 98 & \text { Interviewed university students. } \\ 99 & \text { Chea, supra note } 13 .\end{array}$ 
financial problems. ${ }^{100}$ Additionally, a master thesis student at the Royal University of Phnom Penh found that barriers for women in accessing university include personal factors, financial barriers, family background, and cultural factors. ${ }^{101}$

Based on literature reviews and this research's findings, the three main challenges for young women who lost their opportunities to pursue university were the legal frameworks, institutional mechanisms, and economic, social and cultural issues.

\section{Legal Frameworks}

This research found that many people did not have comprehensive knowledge of some of the laws above; $83.33 \%$ of ministry and NGO officers, $60 \%$ of university lecturers and staff, $45 \%$ of parents in the communities, $45 \%$ of women, and $48.57 \%$ of university students knew some relevant laws and policies to promote or protect women in higher education. However, $16.67 \%$ of all NGO officers said that there are no laws in Cambodia that promote women in higher education and that the government had only policies relevant to the sector.

However, Article 10 of CEDAW, Article 26 of UDHR, and Article 13 (2, c) of ICESCR, protect and promote education to all people. All people can have access to education at all levels without discrimination. The RGC recognizes international laws as mentioned in Article 30 of the Constitution of the Kingdom of Cambodia. Moreover, Article 65 protects and promotes education at all levels to all Cambodian citizens equally to have a better status of living. Furthermore, the RGC also created the Law on Education for enhancing the quality of education at all levels, and it is mandatory for all children to attend school up to grade nine for free. However, there is no specific law to protect and promote women to access higher education without discrimination and as equal to men.

Overall, Cambodia has no specific law to promote and protect women pursuing higher education. In addition, how to disseminate and contribute to relevant laws and policies were limited by some areas and groups of people. After the RGC ratified CEDAW and other relevant international laws, those laws had been limited in its full implementation.

\section{Institutional Mechanism}

For increasing the enrollment of female students in accessing higher education, the government cooperates with NGOs and civil societies. However, the ratio rate of students' enrollment still has a gender gap. Based upon the research's results, most respondents, especially in rural areas, did not know any strategies and

100 Ibid.

101 Sopha Penh, Barriers and Motivation for Female Students at Tertiary Education in Cambodia. A Case study in a University in Phnom Penh (2014). 
activities to promote women accessing higher education. Relevant information to opportunities for women in accessing higher education does not often exist in areas because of limited cooperated relevant institutions.

\section{Economic, Social and Cultural Issues}

According to the findings, currently, most parents are supportive of their daughters pursuing higher education; they want their daughters to have a good future. However, some of these parents cannot send their daughters to university because of financial problems. They also worry about the security of their daughters. ${ }^{102}$ Even in primary school, most female students drop out because they need to help their parents do housework and take care of younger siblings while their parents work. ${ }^{103}$ The cost of high education is higher than the parents' profit. $^{104}$

It is noticeable that the number of female students in provinces was higher than male students because most male students go to study in the capital city. Most women were not allowed to study in Phnom Penh because their parents worry about security and need them to help with housework. ${ }^{105}$ A lack of money to rent a house and a lack of dormitories in Phnom Penh has affect to limitation of women's opportunities to pursue university degrees. Men, on the other hand, can stay anywhere, even at monasteries. Accommodation is a problem mainly for women when leaving home to study at university in the city because men have safer places to stay. It is problematic for women to rent a house in Phnom Penh because many are concerned about security. Even though most of the parents were supportive of their daughters pursing higher education, most respondents still said they prioritize their sons pursing school if there is not an ability to send both children. ${ }^{106}$ Therefore, it is clear that some Cambodians still prioritize sons pursing education over daughters if they lack a budget to support their family or a school fee for both their sons and daughters.

Based upon on the perception of duty-bearers through this research, many thinks that there is still gender-based discrimination for women accessing university in Cambodia. ${ }^{107}$ However, some people assumed that there is no gender discrimination against women in higher education in Cambodia anymore. Nevertheless, the acts of worrying about security for daughters and not allowing them to study far away from home, encouraging daughters to help with housework, and prioritizing sons rather than daughters in case parents do not

\footnotetext{
102 Interviewed parents and young women in the communities as well as university students.

103 Booth, supra note 23.

${ }^{104}$ Ministry of Women \& Affairs, supra note 54.

105 Interviewed parents and young women in the communities as well as university students.

106 Interviewed parents in the communities.

107 Interviewed duty-bearers.
} 
have the ability to support all their children are types of gender discrimination. Additionally, parents send sons to school because they think that the man will become the head of the family after they get married, and if a man has a lower education than the women, the wife will look down on the husband. 108 Accordingly, these are all kinds of discrimination that women face in accessing university. Thus, although it has decreased from the past, there is still discrimination for women accessing higher education in Cambodia. Following the Buddhist belief of reincarnation, if a woman in this life has good traditional practice she will become a man in the next life. ${ }^{109}$

So in Cambodian tradition, women are encouraged to apply traditional practices, including the need to serve her husband, take care of infants at home, and only do housework. These reasons seem to discourage women to pursue higher education. The customs and practices in Cambodia have been a severe root cause in discouraging girls to pursue higher education. Time is needed to change this traditional practice, especially in rural areas. ${ }^{110}$ According to customs and tradition, daughters are not encouraged to attend schools and sons are provided with more opportunities to study because they have a higher status than girls. ${ }^{111}$ Also, it is not easy to send daughters to study far away from home because the parents are afraid for her security and socially it would be bad for the family if their daughter returns home pregnant without being married. ${ }^{112}$ Cambodians have followed the Chab Srey theory for a long time, and it may be hard to change their beliefs and practices. ${ }^{113}$ Chab Srey requires women to serve their husband and take care of infants and property at home; thus, it does not inspire women to commit to higher education. This theory also views men as being the head of the Cambodian family, so men are inspired to pursue higher education.

There are still issues which remain a major challenge in expanding education and training opportunities for girls and women; illiteracy and low levels of parents' education, particularly in rural areas, continues to be a serious problem in ensuring education for girls. Child marriage is still a continuing practice, especially in rural areas. Violence in the home affects education for all children. Additionally, girls with disabilities', lesbians, and transgender persons have higher school absences and drop-out rates due to personal and family situations. Other school-level issues include: violence in school, no safe transportation to and from school, lack of or low levels of hygiene, low education for people in rural areas which affects the access to education for their children, especially girls and

\footnotetext{
108 Interviewed parents and young women in the communities.

109 Booth, supra note 23.

${ }^{110}$ Committee on the Elimination of Discrimination against Women, supra note 55.

111 Ibid.

112 Kasumi Nakagawa, More Than White Cloth?: Women's Rights in Cambodia (Cambodian Defenders Project, 2006).

113 Booth, supra note 23.
} 
women, and a lack of engagement in school activities and children's education from the community and parents remains weak. ${ }^{114}$

\section{CONCLUSION AND RECOMMENDATIONS}

According to the data analysis, female students currently are increasing enrollment at universities. The government and relevant stakeholder have been striving to promote females in the education sector. More people understand the value of education and are reducing their old mindset; they encourage and support their daughters to access higher education. However, the number of female students is still lower than male students in higher education or university. This gap is because of three main factors: institutional mechanisms, the legal framework, and economic, social, and cultural issues. Cambodian people remain in their old, traditional ways when it comes to the concept of women. That is a reason why women cannot pursue higher education. Poverty is also a considerable factor.

As a result, the RGC and relevant stakeholders should improve and continue their good collaborations to expand their support. This support can include scholarships, dormitories, stipend, convenient infrastructure, and other facilities so that young women can study at all levels, especially women from rural areas. The government should enhance strategic plans and activities in order to improve women enrollments in higher education as well as graduate with quality knowledge. Moreover, there ought to be an increase in raising awareness of discrimination against women in all areas. Then, the Cambodia government should strengthen and implement relevant laws to protect and promote women's access to higher education and disseminate country wide. Methods of dissemination could be by social media or education in each of the villages, publications, leaflets, and banners on highways. Economic development for farmers and other community members in rural areas is also important in encouraging parents to persuade their daughter to study at higher education. If familyy conditions are poor, there is less priority for study; the primary need is to work in supporting their families. Thus, the government should find approaches to improve poverty in rural areas. Enforcing laws and policy implementations are also the main tasks of the RGC, and the RGC should monitor and evaluate those projects after completing their actions.

${ }^{114}$ Ministry of Women Affairs, Report on Study of emerging gender issues among women, girls and youth in Cambodia (Pnom Penh, 2011). 


\section{BIBLIOGRAPHY}

African Charter on Human Rights and People's Rights, OAU Doc. CAB/LEG/67/3 rev. 5, 21 I.L.M. 58 (1982), (entered into force 21 October 1986).

Annual Progress Report 2013: Achieving Cambodia's Millennium Development Goals (Pnom Penh, 2014).

Arab Charter on Charter on Human Rights (entered into forced 16 March 2008).

ASEAN Human Rights Declaration and Phnom Penh Statement on the Adoption of the ASEAN Human Rights Declaration (AHRD) (entered into forced February 2013).

ASEAN Human Rights Declaration and Phnom Penh Statement on the Adoption of the ASEAN Human Rights Declaration (AHRD) (entered into forced February 2013).

Booth, Mary N. 'Education and Gender in Contemporary Cambodia' (2014) 4:10 Int J Humanit Soc Sci 9.

Cambodian National Council for Women, Cambodian National Council for Women (2001).

CEDAW, (entered into forced 3 September 1981).

Chowdhury, Azizur Rahman \& Jahid Hossain Bhuiyan, eds. An introduction to international human rights law (Leiden ; Boston: Brill, 2010).

Chea, Nich. 'Higher Education in Cambodia Poor Rural Female Students' challenges, motivations, and coping strategies' (2015), online: https://gupea.ub.gu.se/handle/2077/39995.

Committee on the Elimination of Discrimination against Women. Consideration of reports submitted by States parties under article 18 of the Convention on Convention on the Elimination of All Forms of Discrimination against Women (Cambodia, 2006).

Constitution of the Kingdom of Cambodia, 1993.

Council of Europe. European Social Charter (Revised) (1996).

Council of Europe. Protocol of ECHR, (entered into forced 1 June 2010).

Education for All 2015 National Review Report (Pnom Penh, 2015).

Education Law, NS/RKM/1207/032, (21 November 2007). 
Discrimination against Women in Accessing Higher Education in Cambodia

Education Strategic Plan 2014-2018(Pnom Penh, 2014).

Fry, Peter and Rogéro Utui, Literature Review on Equity and Access to Tertiary Education in the Africa Region, ed (Africa, 2009).

History of MoWA (2017).

Kyllonen, Patrick. La importancia de la educación superior y el rol de los atributos no cognitivos en el éxito en dichas instituciones (2012).

Lemaistre, Anne. Remarked by Mrs. Anne Lemaistre, Chair of Education Sector Working Group (ESWG) UNESCO Representative in Cambodia (2015).

Ministy of Education, Youth \& Sport. Achievement in School Year 2014-2015 \& 2015-2016 (Pnom Penh, 2017).

Ministry of Education Youth \& Sports. Annual Report 2009 and Annual Plan 2010: Enhancing Education Quality Project”, ADB Grant No. 0090 - \{CAM\} ( $\{S F\})$ (Pnom Penh, 2010).

Ministry of Education Youth \& Sports. National Strategic Development Plan 20142018 (Pnom Penh, 2014).

Ministry of Education Youth \& Sports. Policy on Higher Education Vision 2030 (Pnom Penh, 2014).

Ministry of Education Youth \& Sports. The Education, Youth and Sport Performance in the Academic Year 2015-2016 and Goals for the Academic Year 2016-2017, 21-22-23 March 2017 (Pnom Penh, 2017).

Ministry of Planning. Achieving Cambodia's Millennium Development Goals (Pnom Penh, 2010).

Ministry of Woman Affairs. Education: Gender in Education and Vocational Training Cambodia Gender Assessment (Pnom Penh, 2014).

Ministry of Women Affairs. Five Years Strategic Plan for Gender Equality and Empowerment of Women 2014-2018 (Ministry of Women Affairs, 2014).

Ministry of Women Affairs. Report on Study of emerging gender issues among women, girls and youth in Cambodia (Pnom Penh, 2011)Moeckli, Daniel et al, eds. International Human Rights Law, third edition ed (Oxford, New York: Oxford University Press, 2017).

Ministry of Women Affairs. The Implementation of the Beijing Declaration and 
Platform for Action (1995) and the outcomes of the Twenty-third Special Session of the General Assembly (Pnom Penh, 2000).

Nakagawa, Kasumi. More Than White Cloth?: Women's Rights in Cambodia (Cambodian Defenders Project, 2006).

OHCHR. International Covenant on Economic, Social and Cultural Rights (1966).

Optional Protocol of Convention on Elimination of all forms of Discrimination against women (2000).

Organization and Functioning of Ministry of Education Youth and Sport Royal Government of Cambodia, Sub-decree No. 84 ANKr. BK (9 June 2009), article 23. 'Our Work-Cambodia MDG', (2017), online: http://www.kh.undp.org/content/cambodia/en/home/library/mdg.html.

Organization of American States OAS. 'Additional Protocol to the American Convention on Human Rights in the Area of Economic, Social and Cultural Rights (Protocol of San Salvador), 14 November 1988' (1989) 16 Annu Rev Popul Law 1,234.

Penh, Sopha. Barriers and Motivation for Female Students at Tertiary Education in Cambodia. A Case study in a University in Phnom Penh (2014).

Program of Action of the 1994 International Conference on Population and Development (Chapters I-VIII) (1995) 21:1 Popul Dev Rev 187, online: https://www.jstor.org/stable/2137429.

Progress towards the Sustainable Development Goals: Report of the SecretaryGeneral (2017).

Rany, Rany, Ahmad Nurulazam Md Zain \& Hazri Jamil. 'Establishment of Institutional Policies for Enhancing Education Quality in Cambodian Universities' (2012) 1:1 Int J High Educ 112, online: http://www.sciedu.ca/journal/index.php/ijhe/article/view/1024.

Rushdy, Sherif. Achieving Cambodia's Millennium Development: goal-gap analysis (2009).

Sen, Vicheth. 'Cambodia's Higher Education Structure and the Implications of the 2015 ASEAN Economic Community’ (2013) CDRI Annu Dev Rev 24.

Smith, Rhona K M. International human rights law, eighth edition ed (New York, NY: Oxford University Press, 2018). 
Songkaeo, Thammika \& Loke Hoe Yeong. 'Defining Higher Education Issues and Challenges in Southeast Asia/ASEAN within the International Context' (2016) Head Found.

The Cambodian NGO Committee on CEDAW (2017).

The Organization and Functioning of the Ministry of Women's Veteran's Affairs, Sub-Decree No. 88 ANKr. BK (7 October 1999), article 3.

The Role of Higher Education in Society: Quality and Pertinence (Paris, 1991).

UNDP. Gender: Gender Mainstreaming Institutional, Partnership and Policy Context Cambodia Gender Assessment (Pnom Penh, 2014).UNDP. Human Development Report 2015 (New York, 2015).

UNDP. Human Development Report 2016 (New York, 2016).

UNDP. Our Work-Cambodia MDG', (2017), online: http://www.kh.undp.org/content/cambodia/en/home/library/mdg.html.

UNESCO. Global education monitoring report 2017/18: accountability in education : meeting our commitments (2017).

UNESCO Institute for Statistics. Global education digest 2010: comparing education statistics across the world. (Montreal: UNESCO Institute of Statistics, 2010).

UNESCO. UNESCO National Education Support Strategy (Pnom Penh, 2010).

United Nations. Rapid Integrated Assessment - Cambodia SDG Profile Card (Pnom Penh, 2016).

United Nations. United Nations Millennium Declaration (2000).

UN Women. Beijing Declaration and Platform for Action: The Fourth World Conference (Beijing, 1995).

USAID. Gender and Extreme Poverty (2015).

Vision and Mission of MoWA (2017). 
Sophorn Tuy is a Librarian/Researcher at Center for the Study of Humanitarian Law (CSHL) of Royal University of Law and Economics (RULE). This article is restructured from her master thesis at Paññāsāstra University of Cambodia (PUC). 